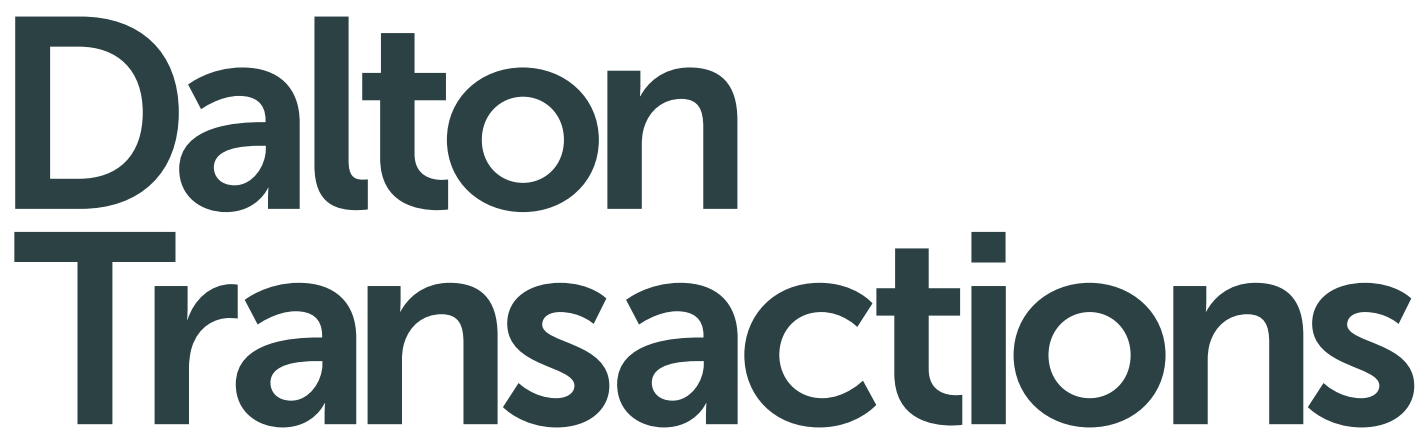

An international journal of inorganic chemistry www.rsc.org/dalton

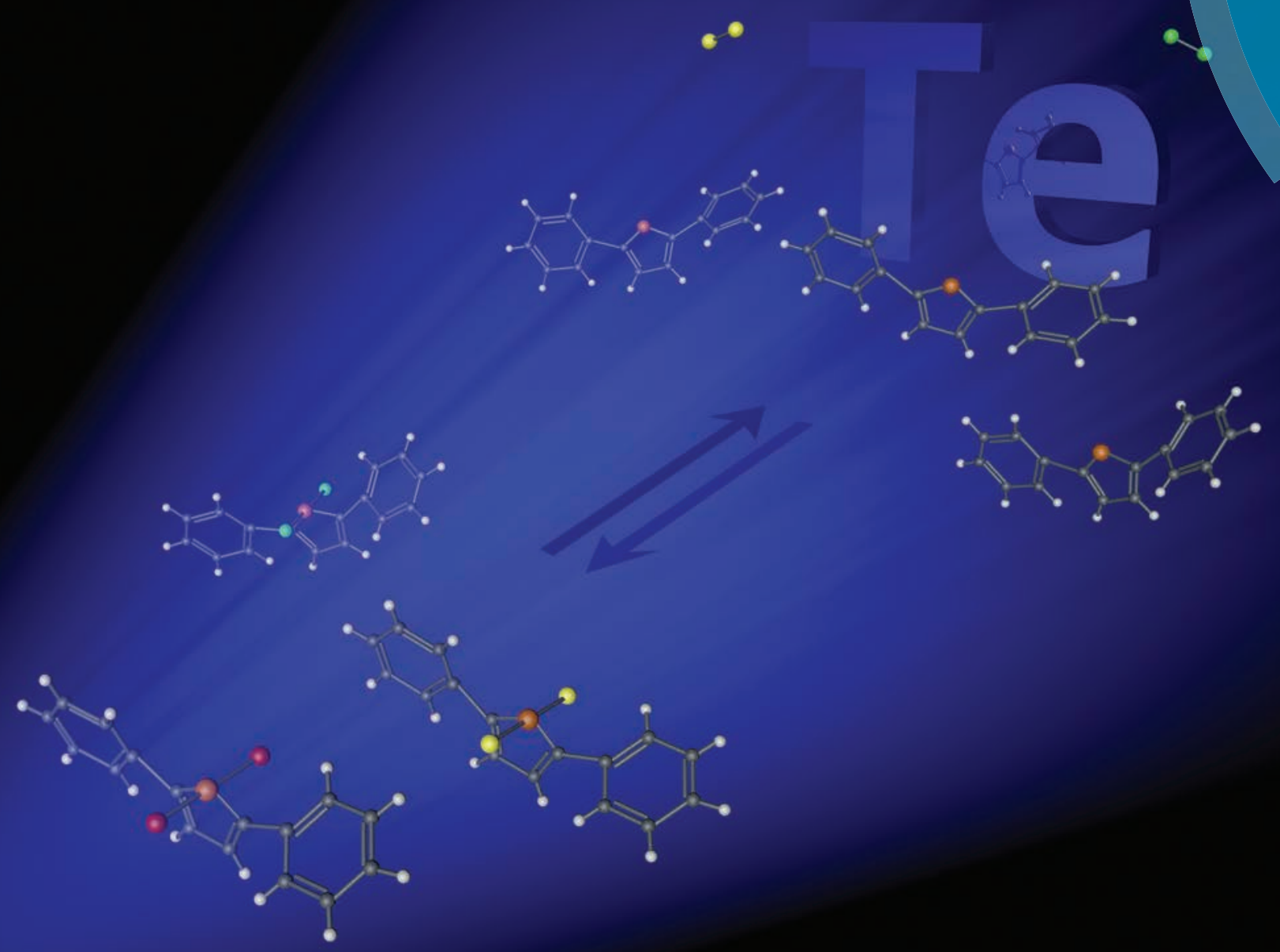




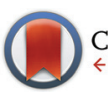

CrossMark \&lick for updates

Cite this: Dalton Trans., 2015, 44 2092

Received 12th June 2014,

Accepted 19th August 2014

DOI: $10.1039 / c 4 d t 01751 j$

www.rsc.org/dalton

\title{
Efficient halogen photoelimination from dibromo, dichloro and difluoro tellurophenes $\uparrow$
}

\author{
Elisa I. Carrera and Dwight S. Seferos*
}

\begin{abstract}
We present the reactivity and photochemistry of 2,5-diphenyltellurophene. A change in oxidation state from $\mathrm{Te}(॥)$ to $\mathrm{Te}(\mathrm{IV})$ occurs by oxidative addition of bromine, chlorine, and fluorine from appropriate halogen sources. Photoreductive halogen elimination is demonstrated using optical absorption spectroscopy and NMR spectroscopy. The photodebromination reaction occurs with $16.9 \%$ quantum yield, the highest value for any Te compound. Photoreductive elimination of chlorine and fluorine occurs with quantum yields of $1.6 \%$ and $2.3 \%$, respectively, albeit with less efficient halogen trapping when an organic trap is used. Improved fluorine trapping was achieved using water, allowing for much cleaner photodefluorination. This is the first example of photodefluorination from a tellurium compound.
\end{abstract}

\section{Introduction}

Tellurium is a metalloid that undergoes oxidation reactions with halogens and other oxidants. ${ }^{1-4}$ Organotellurium compounds including tellurium-containing heterocyclic dyes undergo thermally-driven reductive elimination, ${ }^{3,5}$ however the photochemistry of such compounds has not been extensively studied. In particular, photodehalogenation has been the subject of several recent reports because it is important for catalysis and releasing energy stored in chemical bonds. Gabbaï and coworkers synthesized a dinuclear Te-Pt complex in which $\mathrm{Cl}_{2}$ could be added across the Te and Pt atoms. Lightdriven reductive elimination of chlorine was observed for this complex with a $4.4 \%$ quantum yield. ${ }^{6}$ Our group recently reported the first example of photoreductive elimination of bromine and chlorine from a transition metal-free mononuclear organotellurium compound, 2,5-bis[5-( $N, N^{\prime}$-dihexylisoindigo)]tellurophene. ${ }^{7}$ The extended conjugation through tellurophene to isoindigo allows for the use of $505 \mathrm{~nm}$ (green) light to drive the photoreaction. However, the quantum yields are low, near $0.2 \%$. To put this in context, dehalogenation quantum yields between $5 \%$ and $38 \%$ are considered quite good and have been reported for bimetallic $\mathrm{Pt}-\mathrm{Au}, \mathrm{Au}-\mathrm{Au}$, Pt-Rh, and Pt-Pt complexes, ${ }^{8}$ and recently up to $82 \%$ for a monometallic Pt complex. ${ }^{9}$ Although the primary photoexcitation in the isoindigo-tellurophene system occurs to an excited

Department of Chemistry, University of Toronto, 80 St. George St., Toronto,

ON M5S 3H6, Canada.E-mail: dseferos@chem.utoronto.ca; http://www.chem.utoronto. ca/staff/seferos/

$\dagger$ Electronic supplementary information (ESI) available: Experimental methods, supplementary figures and tables, and computational data. See DOI: 10.1039/c4dt01751j state that has antibonding $\mathrm{Te}-\mathrm{X}$ character, it may rapidly decay to a lower-energy excited state that does not have antibonding $\mathrm{Te}-\mathrm{X}$ character, leading to the relatively poor quantum efficiency. This hypothesis is supported by density functional theory (DFT) calculations. It is therefore important to develop a tellurophene compound where primary photoexcitation occurs to an excited state that has antibonding $\mathrm{Te}-\mathrm{X}$ character and there are no lower lying excited states. Photodehalogenation from these types of tellurophenes have not been reported by us or others.

Herein, we report photoreductive elimination of bromine, chlorine, and fluorine from 2,5-diphenyltellurophene (PT) (Scheme 1). While the dibromo- and dichloro-adducts of PT $\left(\mathbf{P T}-\mathbf{B r}_{2}\right.$ and PT-Cl $\mathbf{C}_{2}$ ) have been previously reported, ${ }^{4,7}$ the difluoro-adduct $\left(\mathbf{P T}-\mathbf{F}_{2}\right)$ is reported here for the first time. We observe photodehalogenation quantum yields of up to $16.9 \%$ for the dibromo-compound at $5 \mathrm{M}$ halogen trap concentration, which is a nearly 100 -fold improvement from previous work and is comparable to efficient transition metal based systems. ${ }^{9}$ The chlorine and even fluorine photoreduction reactions also take place albeit with decomposition reactions when an organic trap is used. Efficient fluorine trapping using water leads to improved photodefluorination reactions with little decomposition. This is the first example of photoreductive defluorination from an organotellurium compound and to the best of our knowledge, the only known photodefluorination reactions occur with organic substrates. ${ }^{10}$

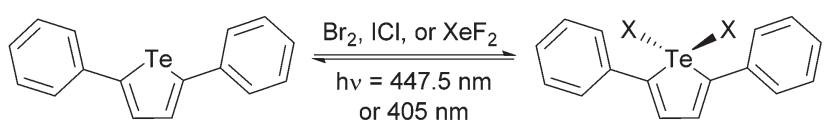

Scheme 1 Oxidative addition and photoreductive elimination of halogens. 


\section{Results and discussion}

DFT calculations were used to determine whether the halogenated compounds (PT- $\mathbf{X}_{2}$ ) would be good candidates for photoreductive elimination. Geometry optimizations and time dependent (TD-DFT) calculations ${ }^{11}$ were performed on PT and the halogen adducts using the Gaussian 09 software suite ${ }^{12}$ at the B3LYP level of theory ${ }^{13}$ with a split basis set (LANL2DZ for $\mathrm{Te},{ }^{14}$ and $6-31 \mathrm{G}(\mathrm{d})$ for all other atoms ${ }^{15}$ ). The TD-DFT calculations predict two strong optical transitions $(f=0.30$ and 0.42) for PT, consisting of transitions from the HOMO to the LUMO and from the HOMO to the LUMO+1. The molecular orbital (MO) diagrams indicate that these are $\pi \rightarrow \pi^{*}$ transitions (Fig. 1a). The LUMO is delocalized across the entire molecule. Upon halogen addition, the energy of the HOMO to LUMO gap
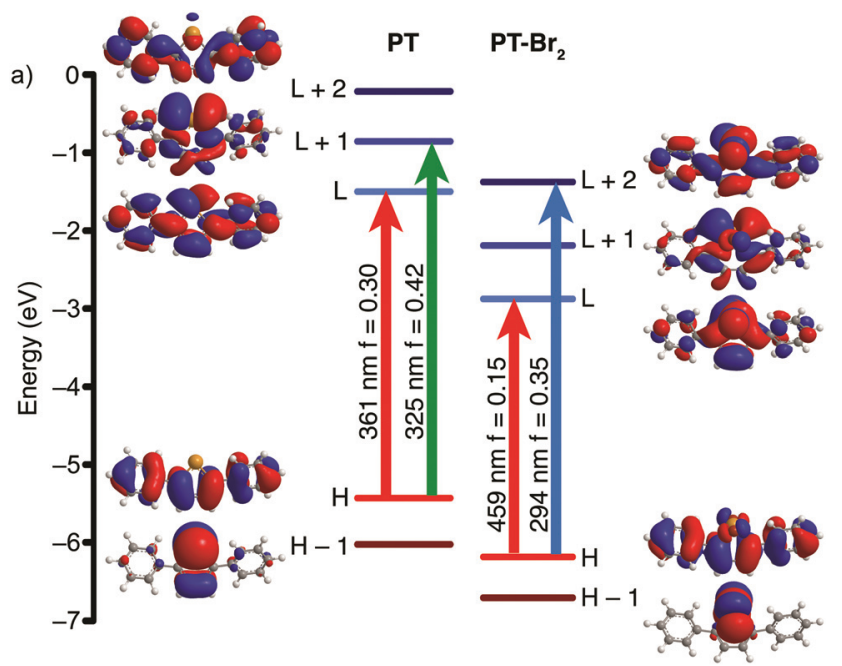

b)
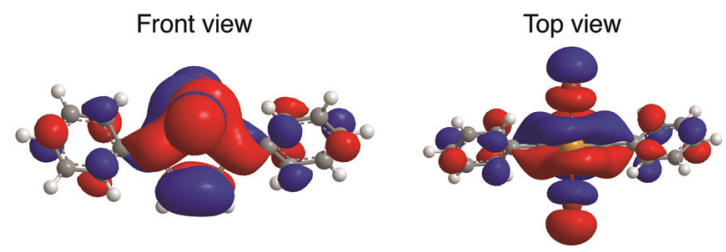

Fig. 1 (a) Excited state transitions of PT and $\mathrm{PT}^{-\mathrm{Br}_{2}}$ with oscillator strength greater than 0.1 as predicted by TD-DFT, and their associated MOs (isocontour value of $0.02 ; \mathrm{H}$ refers to HOMO, L refers to LUMO). (b) Front and top view of the calculated LUMO for PT- $\mathrm{Br}_{2}$. decreases, which in turn leads to a lower energy calculated optical transition. The shift is less pronounced for $\mathbf{P T}-\mathbf{F}_{2}$ and is roughly equal in magnitude for $\mathbf{P T}-\mathbf{B r}_{2}$ and $\mathbf{P T}-\mathbf{C l}_{\mathbf{2}}$ (Fig. S1, ESI $\dagger$ ). Two strong optical transitions are predicted for all three halogenated compounds. The lower energy absorption is dominated by a HOMO $\rightarrow$ LUMO transition, and the LUMO possesses significant Te-X antibonding character (Fig. 1b). The use of the Stuttgart/Dresden $\mathrm{ECP}^{16}$ for tellurium does not lead to significant differences in the DFT results compared to the LANL2DZ basis set. Since the compounds exhibit charge-transfer character, the calculations were also repeated using the long-range correlation functional CAM-B3LYP ${ }^{17}$ with the SDD ECP for tellurium. Similar to our previous work, ${ }^{13 a}$ CAM-B3LYP is less accurate at predicting energy levels than B3LYP due to an underestimation of the HOMO energy, and an overestimation of the LUMO energy (Fig. S2a, ESI $\dagger$ ), resulting in overall higherenergy calculated transitions for $\mathbf{P T}$ and $\mathbf{P T}-\mathbf{B r}_{2}$. A comparison of the calculated and experimental absorption spectra indicates that the B3LYP functional agrees best with experiment, and changing the basis set from LANL2DZ to SDD does not alter the calculated spectra significantly (Fig. S2b-c, ESI $\dot{\dagger}$ ). It is important to note, however, that the nature of the transitions and the MOs remain the same regardless of the functional used, with significant Te-X antibonding character in the LUMO. Population of this state through photoexcitation should therefore promote halogen dissociation.

To test this hypothesis, PT was synthesized according to a modified literature method. ${ }^{4}$ Briefly, tellurium powder was reduced by treatment with sodium borohydride in a refluxing ethanol-water mixture to give sodium telluride. Once the reaction mixture changed from purple to colorless $(1.5 \mathrm{~h})$, the temperature was reduced to $80{ }^{\circ} \mathrm{C}$ and 1,4-diphenyl-1,3-butadiyne was added and heated for $21 \mathrm{~h}$ to give PT in $61 \%$ yield after workup. The oxidized tellurophenes $\mathbf{P T}-\mathbf{B r}_{2}, \mathbf{P T}-\mathbf{C l}_{2}$, and PT- $\mathbf{F}_{2}$ were prepared by reaction with $\mathrm{Br}_{2}$, iodine monochloride (ICl), and xenon difluoride $\left(\mathrm{XeF}_{2}\right)$, respectively. The identity of the newly synthesized compound $\mathbf{P T}-\mathbf{F}_{2}$ was confirmed by NMR spectroscopy and elemental analysis (ESI $\dagger$ ).

Optical absorption titration experiments were carried out on dilute solutions of PT $\left(2 \times 10^{-5} \mathrm{M}\right.$ in chloroform $)$ to monitor the conversion to the halogenated species (Fig. 2). For reference, the absorption spectrum of PT consists of a peak at $342 \mathrm{~nm}\left(\varepsilon=2.24 \times 10^{4} \mathrm{M}^{-1} \mathrm{~cm}^{-1}\right)$ with increasing absorption
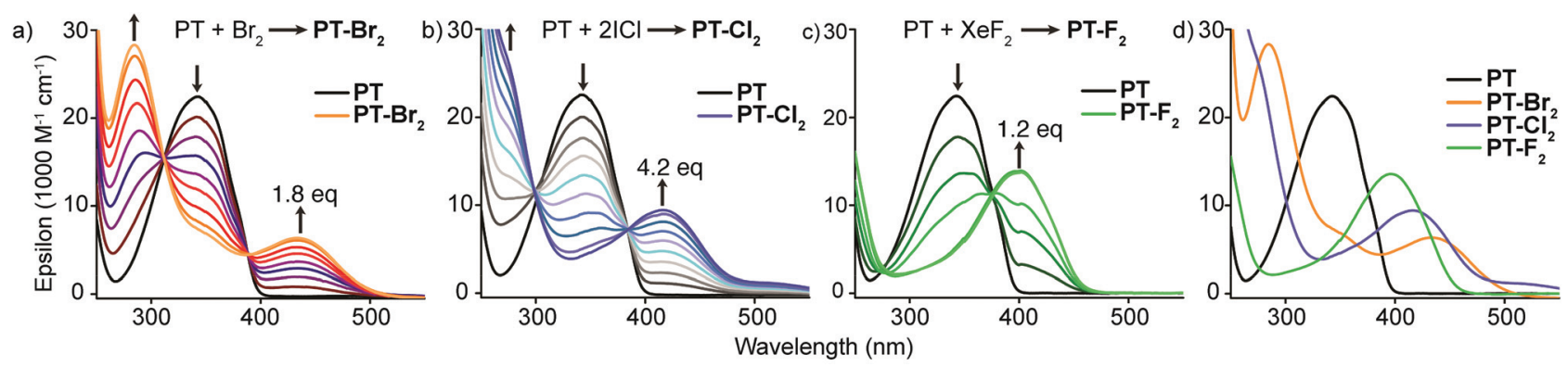

Fig. 2 Optical absorption titration experiments with (a) $\mathrm{Br}_{2}$, (b) $\mathrm{ICl}$, and (c) $\mathrm{XeF}_{2}$; (d) comparison of absorption spectra of PT and its halogenated adducts. 
at wavelengths approaching the high-energy solvent cut-off. Upon halogen addition, the peak at $342 \mathrm{~nm}$ decreases while a red-shifted absorption band develops. The magnitude of the observed red-shift increases moving to heavier halogens $\left(\mathbf{P T}-\mathbf{F}_{2}, \lambda_{\max }=395 \mathrm{~nm}, \varepsilon=1.36 \times 10^{4} \mathrm{M}^{-1} \mathrm{~cm}^{-1} ; \mathbf{P T}-\mathbf{C l}_{2}, \lambda_{\max }=\right.$ $416 \mathrm{~nm}, \varepsilon=9.42 \times 103 \mathrm{M}^{-1} \mathrm{~cm}^{-1}$; PT-Br $2, \lambda_{\text {max }}=433 \mathrm{~nm}, \varepsilon=$ $6.34 \times 10^{3} \mathrm{M}^{-1} \mathrm{~cm}^{-1}$ ). For $\mathbf{P T}-\mathbf{B r}_{2}$, the magnitude of the redshift is large enough to observe the fully resolved dual-band absorption. All of this data is consistent with the TD-DFT calculations described above.

At $2 \times 10^{-5} \mathrm{M}$ concentration, conversion of PT to PT- $\mathbf{F}_{2}$, PT- $\mathbf{C l}_{2}$, and PT-Br ${ }_{2}$ was complete after the addition of 1.25, 4.2, and 1.8 equivalents of halogen source, respectively. Incomplete conversion after stoichiometric addition of halogen was consistent over several experimental runs. In more concentrated solutions, incomplete conversion was also observed by NMR spectroscopy after stoichiometric halogen addition, however higher conversions were achieved compared to the optical absorption titration experiments. This discrepancy suggests that an excess of halogens is required to drive the reaction forward, especially in dilute solution.

Photolysis experiments were carried out at wavelengths corresponding to the low energy absorption peaks of each compound. A $447.5 \mathrm{~nm}$ tri-LED setup was used to irradiate solutions of $\mathbf{P T}-\mathbf{B r}_{2}$ (see ESI $\dagger$ for light source specifications). 2,3-Dimethyl,1-3-butadiene (DMBD) was used as a halogen trap. The change in the absorption spectrum during photoexcitation was used to follow the reaction progress (Fig. 3a). A rapid decrease in the low energy absorption is observed along with an increase in absorption around $340 \mathrm{~nm}$. The final trace is obtained within 12 seconds, and matches well with the spectrum of PT. A slight deviation from the high energy isosbestic point suggests minor decomposition.

Photolysis reactions were carried out on more concentrated solutions and probed by ${ }^{1} \mathrm{H}$ NMR spectroscopy. The symmetric tellurophene protons give rise to a singlet with satellite peaks arising from proton-tellurium coupling. This signature allows for easy identification of the different tellurophene compounds present in solution. Accordingly, $2.5 \mathrm{mM}$ solutions of $\mathbf{P T}-\mathbf{B r}_{2}$ were irradiated in the presence of DMBD $(0.9 \mathbf{M})$ at 5 second time intervals and a spectrum was obtained after each interval (Fig. 3b). During the course of the reaction, the singlet corresponding to the tellurophene protons $(7.42 \mathrm{ppm})$ is depleted and a singlet corresponding to the tellurophene protons of PT develops (7.84 ppm). The changes in chemical shifts of the phenyl proton signals are also consistent with restoration of PT. Evidence of slight decomposition is observed, however these are quite minor and will be discussed below.

Control experiments were carried out to confirm that the reverse reaction is indeed light-driven rather than by other means. Solutions of $\mathbf{P T}-\mathbf{B r}_{2}$ in the presence of $1 \mathrm{M}$ DMBD showed no change in the ${ }^{1} \mathrm{H}$ NMR spectrum after 45 hours in the dark. When exposed to room lighting, PT was restored within 45 hours (Fig. S3, ESI†). In the absence of trap, the ${ }^{1} \mathrm{H}$ NMR spectrum of $\mathbf{P T}-\mathbf{B r}_{2}$ was unchanged when stored in the dark, but showed slow conversion to PT when exposed to room lighting (30\% after 6 days; Fig. S4, ESI $\dagger$ ). Finally, a solution of PT-Br $\mathbf{B}_{2}$ was irradiated with $447.5 \mathrm{~nm}$ light in the absence of trap. The ${ }^{1} \mathrm{H}$ NMR spectrum shows evidence of restored PT, however a significant amount of decomposition occurs (Fig. S5, $\mathrm{ESI} \dagger$ ). In the presence of trap, most of the liberated bromine reacts with $\mathrm{DMBD}$, however a small amount reacts with the conjugated tellurophene, leading to minor decomposition as evidenced by ${ }^{1} \mathrm{H}$ NMR and optical absorption spectroscopy.

In order to quantify the efficiency of the photoreductive elimination reaction, the photochemical quantum yield $(\Phi)$ was determined using potassium ferrioxalate standard actino-

Table 1 Quantum yields for photoreductive elimination from $\mathrm{PT}-\mathrm{Br}_{2}$ with varying trap concentration

\begin{tabular}{lcl}
\hline$[\mathrm{DMBD}](\mathrm{M})$ & Quantum yield, $\Phi^{a}(\%)$ & Standard dev. $(\%)$ \\
\hline 0.1 & 3.1 & 0.1 \\
0.5 & 4.3 & 0.2 \\
0.9 & 5.9 & 0.4 \\
2 & 8.5 & 0.3 \\
3 & 11.0 & 0.6 \\
4 & 14.1 & 0.2 \\
5 & 16.9 & 0.6
\end{tabular}

${ }^{a}$ Determined by potassium ferrioxalate actinometry.
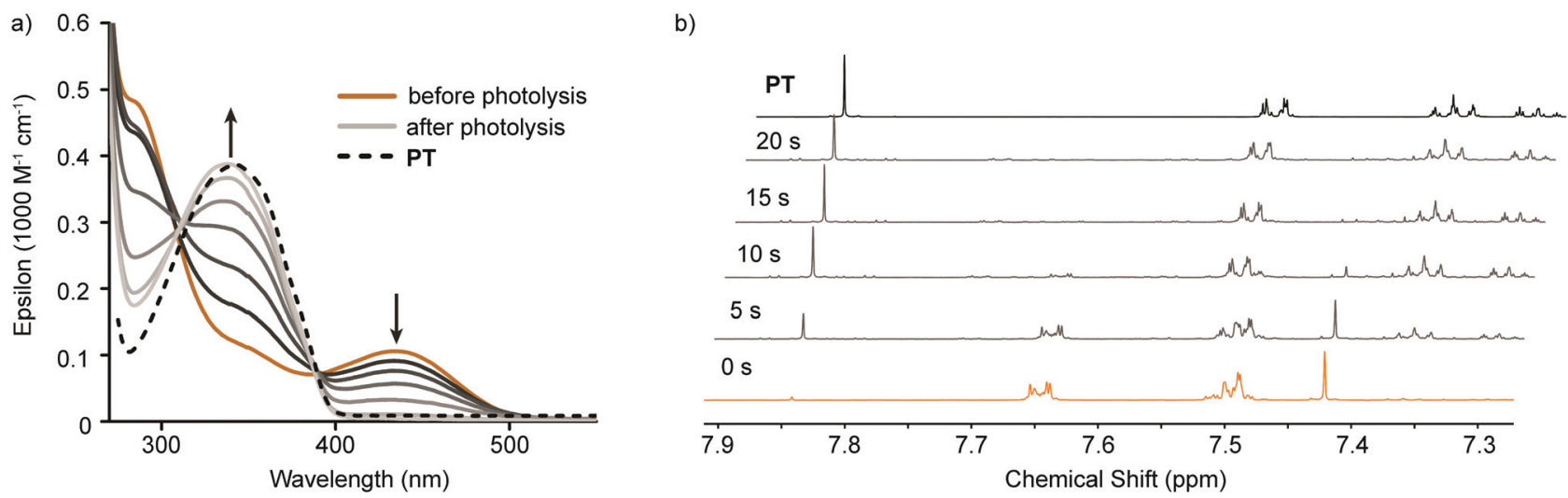

Fig. 3 Photolysis of PT- $\mathrm{Br}_{2}$ with $447.5 \mathrm{~nm}$ light over time monitored by (a) optical absorption spectroscopy and (b) ${ }^{1} \mathrm{H}$ NMR spectroscopy. 
a)

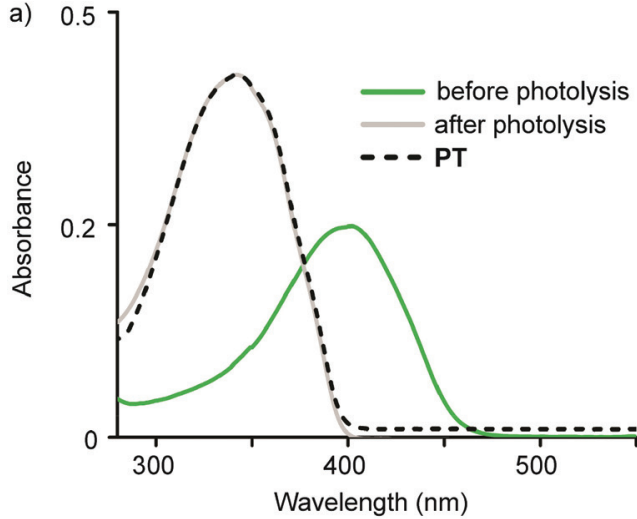

b)

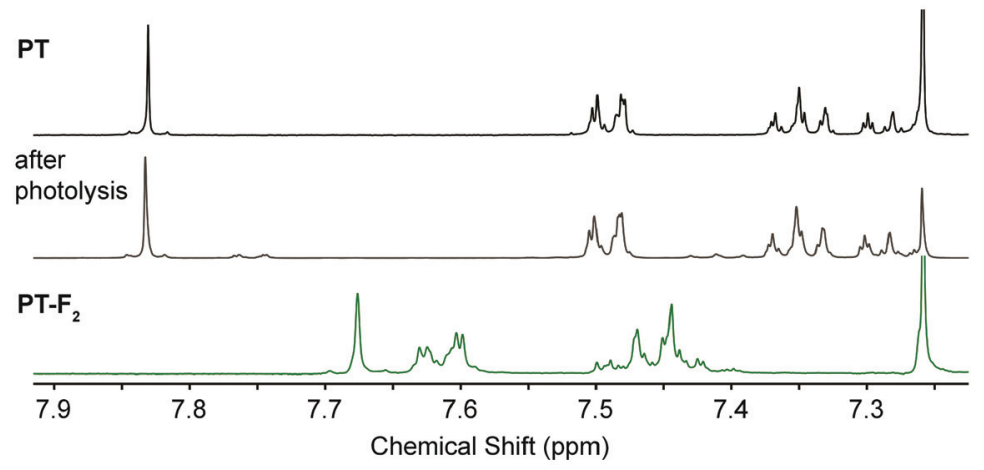

Fig. 4 Bulk photolysis of PT- $\mathrm{F}_{2}$ in $\mathrm{THF}-\mathrm{H}_{2} \mathrm{O}$ with $447.5 \mathrm{~nm}$ light over time monitored by (a) optical absorption spectroscopy and (b) ${ }^{1} \mathrm{H}$ NMR spectroscopy.

metry (details provided in the ESI $\dagger$ ). ${ }^{18}$ At 2 M DMBD concentration, the quantum yield is $8.5 \%$, and a linear increase in quantum yield is observed with increasing trap concentration $\left(y=2.7732 x+2.9707, R^{2}=0.9981\right.$; Table 1$)$. At the highest experimental DMBD concentration (5 M), the quantum yield of photodebromination is $16.9 \%$. This is the first example of efficient dehalogenation from a compound that does not contain a metal.

Analogous photolysis experiments were carried out on solutions of PT- $\mathbf{C l}_{2}$ and PT-F $\mathbf{F}_{2}$, using a $447.5 \mathrm{~nm}$ tri-LED and a $405 \mathrm{~nm}$ LED, respectively. Photoreductive elimination of both chlorine and fluorine is successful $\left(\Phi_{\mathrm{PT}-\mathrm{Cl} 2}=1.6 \%\right.$ and $\Phi_{\mathrm{PT}-\mathrm{F} 2}=$ $2.3 \%$ as calculated from the loss of halogenated compound in solution); however, decomposition products are observed. The optical absorption spectra after photolysis are skewed to higher energies compared to PT (Fig. S6, ESI $\dagger$ ). This suggests that although reductive elimination of chlorine and fluorine is successful, decomposition products are formed in significant proportions. This is further supported by the ${ }^{1} \mathrm{H}$ NMR spectra of photolyzed samples (Fig. S7, ESI $\dagger$ ). In these cases, it is likely that the liberated halogens are more reactive toward PT than the trap, leading to a large proportion of decomposition products. Given the extremely high reactivity of fluorine with water to produce $\mathrm{HF},{ }^{19}$ photodefluorination was carried out on a biphasic mixture of $\mathbf{P T}-\mathbf{F}_{2}$ in chloroform and water, in the absence of DMBD. Here we observe less decomposition by ${ }^{1} \mathrm{H}$ NMR spectroscopy due to improved fluorine trapping by water. Fluorine trapping was even further improved when trapping events were no longer limited to the interface between organic and aqueous phases and photolysis experiments were carried out in $\mathrm{THF}-\mathrm{H}_{2} \mathrm{O}$ mixtures $(35: 65$; see $\mathrm{ESI} \dagger$ for Experimental details). As a result, little decomposition of PT is observed by ${ }^{1} \mathrm{H}$ NMR, ${ }^{19} \mathrm{~F}$ NMR, and optical absorption spectroscopy (Fig. 4 and Fig. S8, ESI $\dagger$ ). Additionally, analysis of the aqueous phase after work-up shows a decrease in $\mathrm{pH}$ (qualitatively, using $\mathrm{pH}$ paper) and a peak at $-129.6 \mathrm{ppm}$ in the ${ }^{19} \mathrm{~F}$ NMR spectrum, which is consistent with the presence of $\mathrm{F}^{-}$in aqueous solutions of $\mathrm{HF}^{20}$ Bulk photolysis on a larger scale led to $77 \%$ isolated yield of recovered $\mathbf{P T}$.

\section{Conclusions}

We have shown that 2,5-diphenyltellurophene can be oxidized in the presence of bromine, chlorine, and fluorine and the halogens can be photoreductively eliminated by photoexcitation into the low energy absorption band of the halogenated species. Photoreductive elimination of bromine occurs rapidly with $16.9 \%$ quantum efficiency and minimal decomposition using $447.5 \mathrm{~nm}$ blue light. The $16.9 \%$ quantum yield achieved is comparable to the performance of several transition metal catalysts reported in the literature. Photoreductive elimination of chlorine and fluorine also occurs in the presence of organic trap, albeit with decomposition reactions. However, a significant improvement in fluorine trapping is realized when water is used as a halogen trap, leading to restoration of the reduced tellurophene in $77 \%$ isolated yield and very little evidence of decomposition. This is the first example of photoreductive elimination of fluorine from an inorganic compound, and is an unexpected result given the strength of typical M-F bonds. Improving the quantum efficiency of halogen photoreductive elimination reactions is currently under investigation.

\section{Acknowledgements}

This work was supported by NSERC, the CFI, The Ontario Research Fund, DuPont (for a Young Professor Grant), and the Alfred P. Sloan Foundation (for a Research Fellowship in Chemistry).

\section{Notes and references}

1 M. R. Detty and A. E. Friedman, Organometallics, 1994, 13, 533-540.

2 M. R. Detty, A. E. Friedman and M. McMillans, Organometallics, 1994, 13, 3338-3345.

3 M. R. Detty and H. R. Luss, Organometallics, 1986, 5, 22502256. 
4 T. M. McCormick, A. A. Jahnke, A. J. Lough and D. S. Seferos, J. Am. Chem. Soc., 2012, 134, 35423548.

5 (a) M. R. Detty, Organometallics, 1991, 10, 702-712;

(b) M. R. Detty and T. M. Frade, Organometallics, 1993, 12, 2496-2504; (c) A. A. Jahnke, G. W. Howe and D. S. Seferos, Angew. Chem., Int. Ed., 2010, 49, 10140-10144.

6 T.-P. Lin and F. P. Gabbaï, J. Am. Chem. Soc., 2012, 134, 12230-12238.

7 E. I. Carrera, T. M. McCormick, M. J. Kapp, A. J. Lough and D. S. Seferos, Inorg. Chem., 2013, 52, 13779-13790.

8 (a) T. R. Cook, Y. Surendranath and D. G. Nocera, J. Am. Chem. Soc., 2009, 131, 28-29; (b) T. R. Cook, Y. Surendranath and D. G. Nocera, J. Am. Chem. Soc., 2009, 131, 28-29; (c) T. S. Teets and D. G. Nocera, J. Am. Chem. Soc., 2009, 131, 7411-7420; (d) T. S. Teets, D. A. Lutterman and D. G. Nocera, Inorg. Chem., 2010, 49, 3035-3043; (e) T. R. Cook, B. D. McCarthy, D. A. Lutterman and D. G. Nocera, Inorg. Chem., 2012, 51, 5152-5163; (f) D. C. Powers, M. B. Chambers, T. S. Teets, N. Elgrishi, B. L. Anderson and D. G. Nocera, Chem. Sci., 2013, 4, 28802885.

9 A. R. Karikachery, H. B. Lee, M. Masjedi, A. Ross, M. A. Moody, X. Cai, M. Chui, C. D. Hoff and P. R. Sharp, Inorg. Chem., 2013, 52, 4113-4119.

10 (a) J. Cheng, X. Liang, S. Yang and Y. Hu, Chem. Eng. J., 2014, 239, 242-249; (b) H. Hidaka, T. Tsukamoto, T. Oyama, Y. Mitsutsuka, T. Takamura and N. Serpone, Photochem. Photobiol. Sci., 2013, 12, 751-759; (c) J. Burdeniuc,
P. E. M. Siegbahn and R. H. Crabtree, New J. Chem., 1998, 22, 503-510.

11 R. Bauernschmitt and R. Ahlrichs, Chem. Phys. Lett., 1996, 256, 454-464.

12 M. J. Frisch, et al., GAUSSIAN 09, (Revision A.1), Gaussian, Inc, Wallingford, CT, 2009.

13 (a) T. M. McCormick, C. R. Bridges, E. I. Carrera, P. M. DiCarmine, G. L. Gibson, J. Hollinger, L. M. Kozycz and D. S. Seferos, Macromolecules, 2013, 46, 3879-3886; (b) A. D. Becke, J. Chem. Phys., 1993, 98, 5648-5652; (c) A. D. Becke, J. Chem. Phys., 1996, 104, 1040-1046.

14 P. J. Hay and W. R. Wadt, J. Chem. Phys., 1985, 82, 270-283. 15 W. J. Hehre, R. Ditchfield and J. A. Pople, J. Chem. Phys., 1972, 56, 2257-2261.

16 (a) J. S. Gancheff, P. A. Denis and F. E. Hahn, J. Mol. Struct. (THEOCHEM), 2010, 941, 1-9; (b) M. Dolg and X. Cao, Chem. Rev., 2012, 112, 403-480.

17 (a) T. Yanai, D. P. Tew and N. C. Handy, Chem. Phys. Lett., 2004, 393, 51-57; (b) S. Kupfer, J. Guthmuller and L. González, J. Chem. Theory Comput., 2013, 9, 543-554.

18 (a) C. A. Parker, Proc. R. Soc. London, Ser. A., 1953, 220, 104-116; (b) C. G. Hatchard and C. A. Parker, Proc. R. Soc. London, Ser. A., 1956, 235, 518-536; (c) H. J. Kuhn, S. E. Braslavsky and R. Schmidt, Pure Appl. Chem., 2004, 76, 2105-2146.

19 (a) F. Fichter and W. Bladergroen, Helv. Chim. Acta, 1927, 10, 549-552; (b) G. H. Cady, J. Am. Chem. Soc., 1935, 57, 246-249.

20 J. B. Gerken, J. Fluorine Chem., 2011, 132, 68-70. 